\title{
Interactive Whiteboards in Mathematics Spaces: An Examination of Technology Integration in an Urban Middle School
}

\author{
Jamaal Young \\ University of North Texas, United States \\ Christina Hamilton \\ Texas A\&M University Central Texas, United States \\ Marti Cason \\ University of North Texas, United States
}

\begin{abstract}
The purpose of this study was to examine the effects of integrating Interactive Whiteboard (IWB) technology on middle school mathematics achievement in an urban school. Propensity score matching was used to create a comparable control group in order to isolate the effects of IWB technology on mathematics achievement. An initial experimental group $(n=716)$ of ethnically diverse urban students receiving IWB instruction was matched to a control population $(n=856)$ based on propensity scores generated from demographic and ability data. Student achievement data were analyzed with $2 \times 4$ ANOVA to access treatment main effects and the effects of demographic variables such as gender, ethnicity, and ability. Ethnicity was a significant moderator of the effects. Specifically, a positive effect size was observed for White students, and the achievement gap was also reduced for Hispanic students. Implications for mathematics pedagogy with an IWB are provided based on these conclusions.
\end{abstract}

Keywords: Technology integration; Interactive whiteboard; Mathematics; Achievement gap

\section{Introduction}

The influence of technology on mathematics achievement remains a pedagogical concern. This concern is proliferated by the constant influx of technology in the everyday lives of school-age children (Hsin, Li, \& Tsai, 2014). Many researchers have posited that technology integration in the mathematics classroom transforms learning and creates an environment that captures the attention of digital learners (Grady, Watkins, \& Montalvo, 2012; Hallett, Nunes, \& Bryant, 2010; Jones, Irvin, \& Kibe, 2012; Whyte, Beauchamp, \& Alexander, 2014). Yet, this was not always the case. The integration of desktop computers in the late 1980s marked a shift in the perceptions of the tools necessary to teach mathematics effectively (Jacobsen, Clifford, \& Friesen, 2002). Subsequently, decades of mathematics education research consistently conclude that digital technology, such as computers and calculators, improve mathematics attitudes and problem solving without adversely affecting computational skills (Cheung \& Slavin, 2012, 2013; Drijvers, 2013). As a result, the calculator is recognized as an indispensable tool in many mathematics classrooms (NCTM, 2000). Similarly, the interactive white board (IWB) has slowly replaced traditional dry-erase and chalkboards in many mathematics classrooms (Beauchamp \& Kennewell, 2013; Torff \& Tirotto, 2010). 
Technology use in $\mathrm{K}-12$ urban classrooms is currently declining, causing some to conclude that effective integration of computer technology into urban classroom instruction has yet to be realized (Keengwe \& Akyeampong, 2010; Young \& Young, 2012). Despite the rapid adoption of the IWB across the globe, urban classrooms are the last places to receive access to technologies like the IWB (Kidd \& Jared, 2010). However, the affordances of the IWB can transform teaching and learning in the urban mathematics classroom. Thus, the purpose of this study was to examine the effects of integrating IWB technology on middle school mathematics achievement. The next section provides a contextualized description of the instructional affordances of the IWB in the mathematics classroom.

\section{Interactive Whiteboards in the Mathematics Classroom}

One of the myths about the IWB is that it is an electronic dry-erase board. A dry-erase board shares many of the same affordances as an IWB; however, the constraints of the dry-erase board alter the specific technological pedagogical content knowledge (TPACK) needed to teach effectively. Both the dry-erase board and the IWB allow a teacher to handwrite information on a large, visible area in multiple colors and sizes. Teachers can also erase and modify the content in pretty much the same manner on either tool. Teachers using a dry-erase board are constrained by their ability to rapidly create the content for each example, erase it, and create the next example. However, the IWB allows teachers to almost effortlessly switch between different examples and representations because the content can be loaded in digital form so that the teacher can toggle between examples. This reduces time wasted on transitions and dramatically increases the overall amount of time spent delivering instruction (Beauchamp \& Kennewell, 2010; Turel \& Johnson, 2012).

Maintaining an adequate pace in a mathematics lesson is important to the overall lesson success, and the IWB supports lesson pacing as well. Specifically, the pace of mathematics lessons is increased because the instructor does not have to expend time conceptualizing the next question, writing it on the board, or adjusting the periphery accordingly to suit the next task (Morris, 2010). This in turn creates more class time to explore more examples and thus increases the depth of the discussion. The questions that arise due to the nature of the IWB's flexibility may be difficult for some teachers to facilitate. Therefore, any time that could be saved in the question-posing component releases more time for discourse. It is prudent to note, however, that when teachers are not prepared or the technology fails, using the IWB can inhibit pacing and reduce time on task.

In addition to the improvement of lesson pacing, the IWB promotes the adaptation of lessons to meet the individual needs and curiosities of a diverse population of learners. The IWB supports mathematics discourse by allowing the teacher to filter questions and use alternative resources to answer questions. For instance, the IWB affords teachers time-saving and real-time instructional strategies that capture students' spontaneous curiosity or address misunderstanding by allowing teachers to access pre-created lessons, assessments and/or content (Beauchamp \& Kennewell, 2010). Addressing spontaneous questions that arise during classroom discussion forces the teacher to deviate from the order of the IWB presentation, again indicating that teacher-preparedness with the IWB is important. Engaging student curiosity promotes the inclusion of multiple representations, which are an essential component of effective mathematics instruction. Furthermore, the representations created by technology such as the IWB reveal different features and procedures, which have the potential to affect 
students' thinking processes and learning (Digregorio \& Sobel-Lojeski, 2010; Turel \& Johnson, 2012). This is just one example of how the IWB can create a digital bridge between mathematics pedagogy and digital learning.

The key features of the IWB afford teachers access to a wide array of innovative and motivating resources (Winzenried, Dalgarno, \& Tinkler, 2010). These key features include: (a) centrality in the classroom, (b) interactivity, (c) adaption to different learning styles, (d) and the ability to record and store materials (Miller \& Glover, 2002). These features enhance student learning by facilitating instructional opportunities for students and teachers that are structured, engaging, individual, procedural, and cultural (Hawkes \& Cambre, 2001, p. 1), all of which help support the differentiation of instruction in the mathematics classroom. In the sections that follow, each of the key features is examined in the context of the mathematics classroom.

\section{Centrality}

The centrality of the IWB in the classroom is both an affordance and a hindrance to mathematics instruction. Critics of the IWB suggest that the tool promotes didactical rather constructive educational practices (Greiffenhagen, 2000). Much of this criticism stems from the fact that the IWB is a presentation device, which may lead some teachers to embrace a teacher-centered instructional approach. However, the IWB allows the teacher to act as a mediator between the instructional content placed on the IWB and students, which is indicative of a social constructivist model of instruction (Warren, 2003). According to Wood (1998), the most effective learning takes place when the objective is intelligible but not easily attainable without assistance. The teacher's role in utilizing the IWB is to present complex instructional tasks that the entire class can discuss synchronously. This allows the teacher to engage the students in class discussions through dialogic teaching (Erdogan et al., 2010) and "encourage students to participate actively, using whole-class and group-based discussions to articulate, reflect upon and modify their own understanding" (Mercer, Warwick, Kershner, Kershner, \& Kleine, 2010, p. 369). Mercer et al. (2010) concluded that the IWB can be used to develop a collaborative discussion space because data is easily manipulated so that the entire class can participate in the discourse and make suggestions that can be implemented instantaneously. Such interactivity is a major pedagogical affordance of the IWB in the mathematics classroom.

\section{Interactivity and Lesson Delivery}

Mathematics requires the educator to organize the lesson in a manner that best suits the needs of the learners. The large, interactive instructional area of the IWB allows students to construct mathematics knowledge through project-based, self-directed learning activities that maximize the affordance of technology in the mathematics classroom (Erdogan et al., 2010). The need for peripherals, such as manipulatives, calculators, rulers, and protractors, coupled with the nature of mathematics instruction requires the adequate use of all instructional time for interactive learning experiences. Utilizing digital technology, teachers can effortlessly provide classroom demonstrations and explorations, stimulate group work, and facilitate homework assignment (Schneiter, 2010). Thus, it is imperative that teachers leverage the affordances of operating with an IWB by simply transforming their thinking concerning teaching and learning with technology. This can be difficult when many teachers perceive the primary purpose of technology integration 
as the automaticity of traditional teaching methods (Brandt, 1995). Contrarily, integrating technology into the mathematics classroom requires creativity and imagination (Bates \& Poole, 2003). Although the general features of the IWB promote interactivity, the more specific features that allow teachers to address the diverse learning needs of students are dependent on the skills, knowledge, and creativity of the teacher.

\section{Learning Styles}

Creativity, knowledge, and skills allow teachers to utilize the IWB's ability to address multiple intelligences in order to differentiate instruction (Chen, Chiang \& Lin, 2013; DeMonte, 2013; Littleton, Twiner, \& Gillen, 2010). A full examination of multiple intelligences is beyond the scope of this discussion, though they are a major benefit of the IWB; however, a brief overview of multiple intelligences in the context of mathematics teaching and learning is applicable. The theory of Multiple Intelligence (MI) posits a set of human intellectual capacities, about eight intelligences, in every individual (Al-Onizat, 2016, p. 109). These intelligences are: (a) linguistic, (b) logical-mathematical, (c) spatial, (d) bodily-kinesthetic, (e) musical, (f) intrapersonal, (g) interpersonal, and (h) natural (Gardner, 2001). These capacities are well researched, contextualized, and even criticized. Previous studies have examined factors that mitigate multiple intelligences such as age, gender, parental beliefs, and ethnicity (Goodnow \& Collins, 1990; Han, 2007; Lee, 2006; Razmjoo, 2008). Nonetheless multiple intelligences remain widely accepted within the educational research community.

The efficiency, flexibility, and versatility of the IWB as a teaching tool allow the IWB to support the multiple needs of learners in each lesson (Chen, Chiang, \& Lin, 2013; Demonte, 2013). The most obvious of the intelligences addressed by the IWB are spatial, linguistic, and bodilykinesthetic. The large visual display of the IWB with its vast array of colors and shapes makes this tool conducive to delivering highly visual instruction. This has translated into some success with visual learners, who may be motivated by the capacity of the IWB to display high-quality visual images, which satisfies the expectations of students who are accustomed to visual stimuli (Demonte, 2013). In a study of student views concerning learning with an IWB, Wall, Higgins, and Smith (2005) found that students ranked the visual nature of the IWB high on their list of the learning advantages of the IWB, along with (a) facilitation of discussion, (b) use of different software, (c) initiation of learning, and (d) use of games.

The interactivity of the IWB has been cited as one of the most notable features of the tool for sustained engagement and learning (Bunce, Flens, \& Neiles, 2010; DeMonte, 2013). This is partially because the interactivity meets the needs of bodily-kinesthetic learners by allowing them to physically interact with the board (Beeland, 2002; Bell, 2002). However, if interactivity of the IWB is not utilized, the tool may reinforce teacher-centered rather than learner-centered instruction (Sarsa \& Soler, 2011). Kennewell, Tanner, Jones, and Beauchamp (2008) asserted that the invention of the IWB could be seen as a step backward because it may give new impetus to teacher-centered approaches (p. 71). The interactive features of the IWB are the primary tools teachers can use to create engaging learning activities for students, which are key to maximizing the functionality of the IWB. Some of the physical interactions that can take place with an interactive whiteboard are: (a) drag and drop, (b) hide and reveal, (c) highlighting, and (d) movement/animation (Glover, Miller, Averis, \& Door, 2007). All of these types of interaction allow immediate feedback to students, which is a major benefit for student learning and lesson pacing. Beyond student learning and lesson delivery, the IWB has several practical benefits, one of which is the ability to restore and retrieve lesson content. 


\section{Stored Content}

Teachers may use the ability of the IWB to record and save classroom interactions and activity as a mechanism to maintain lesson pacing when time is sensitive. The ability to save and recycle materials previously created or annotated reinforces and extends the learning over a sequence of lessons (Smith et al., 2005; Walker, 2002). It is important for students to have the ability to review lesson materials and examples several times, since mathematics can oft times be abstract. Furthermore, having access to prior lessons may help students build on prior knowledge and educators locate and diagnose misconceptions. As with all classroom technology, the teacher's use of it is paramount. Wood and Ashfield (2008) concluded, "It is the skill and professional knowledge of the teacher that mediates interactions with technology and thus facilitates the development of pupils' responses to technology" (p. 84). A similar conclusion was found in the case study "Teaching and Learning With an Interactive Whiteboard: A Teacher's Journey"; a teacher named Sue found that it was not simply the IWB, but how she chose to use it, that made the difference in her teaching (Hodge \& Anderson, 2007).

\section{Purpose}

The benefits of the IWB-such as centrality, interactivity, and material recycling-are major affordances of the technology for mathematics instruction; however, there is little quantifiable evidence to substantiate the claim that the IWB is the sole contributor to student engagement and achievement (Smith et al., 2005). The IWB is not a technology cure-all, nor will it foster fundamental changes in pedagogy in and of itself (Smith, Hardman, \& Higgins, 2006). The maximization of the benefits of the IWB involves the exploitation of these, as well as other, affordances of the tool, but this cannot be realized without a commitment to professional development and teacher knowledge (Armstrong et al., 2005). According to Higgins, Beauchamp, and Miller (2007), the research literature is void of consistent examples of how the IWB can promote instructional and pedagogical changes that yield changes in student learning. This is especially true for research related to student learning in urban environments. Thus, this study examined the following questions:

(1) What is the impact of the integration of IWB technology on mathematics achievement in an urban middle school?

(2) After receiving instruction with the IWB, can achievement be differentiated by student gender, race, or ability?

\section{Methodology}

A quasi-experimental design was utilized in this quantitative study. By definition, a quasiexperiment is "an experiment where units are not assigned to conditions randomly" (Shadish, Cook, \& Campbell, 2002, p. 12). As part of this design, teachers were not randomly assigned to particular students or vice versa, nor were specific types of IWB technologies randomly or purposely assigned. The assignments were made through administrator selection and not by self-selection. Therefore, teachers did not decide which students they wanted to teach because the selection had been predetermined. An artifact of the district was that two different IWB tools were in use and, therefore, represented in this study. The majority of the teachers used MimioBoard ${ }^{\mathrm{TM}}$, while a small minority of the teachers utilized the Interwrite ${ }^{\mathrm{TM}}$ Board. No specific 
generalization about the suitability or usability of one over the other was made. Eight teachers participated in the study. These teachers taught the experimental group, which consisted of 716 students. The control group did not receive IWB instruction and consisted of 856 students. All students attended the same urban school district, which is considered low income and serves students who are predominately Latino/Hispanic. The majority of the students received free or reduced lunch $(92.3 \%)$, which is an indicative of children experiencing poverty. Student achievement data were collected on the Mathematics Texas Assessment of Knowledge and Skills (TAKS). This exam is a multiple-choice, criterion-referenced exam given to all middle school students in the state of Texas, a southern state in the United States.

\section{Statistical Analysis}

The student achievement data were analyzed by means of propensity score matching, which was proposed by Rosenbaum and Rubin (1983) for estimating the effects of nonrandomized experiments. Since this was a nonrandom experiment, it was important that the treatment and control groups were similar across a multitude of characteristics in order to isolate the treatment effects in this study. These characteristics are multidimensional and can include race, socioeconomic background, and prior achievement, as well as numerous other factors. Rosenbaum (1998) proposed reducing these characteristics into a single scalar, or summary score, known as the propensity score. The propensity scores for this study matched between treatment and control groups on the following student characteristics: ethnicity, gender, school, grade, gifted status, English as Second Language (ESL) services, and Limited English Proficiency (LEP) services. The scores were calculated by binary logistic regression and saved to the initial SPSS file.

Binary logistic regression was chosen over other methods such as discriminant analysis for two reasons. The first reason is because logistic regression is a robust method that is not subject to a plethora of assumptions. Second, logistic regression allows the user to utilize both categorical as well as scale variables. The logistic regression covariates were ethnicity, gender, and grade level. These covariates were used to determine the student's probability of being in the treatment group; thus, treatment was the dependent variable. The overall fit of the binary logistic model was assessed by the Hosmer and Lemeshow chi-square test for goodness of fit. The differences in the achievement data were compared using a $2 \times 4$ Analysis of Variance (ANOVA). Mean differences in student achievement between the treatment and control groups were assessed, as well as mean differences between the following ethnicity groups: Black, Hispanic, Asian, and White.

\section{Results}

Mathematics TAKS scores on the $6^{\text {th }}, 7^{\text {th }}$, and $8^{\text {th }}$, grade mathematics TAKS for participating students $(n=716)$ were compared to students in the control group $(n=856)$. Tables $1-3$ show the differences between the participating students and the control sample before matching. The students in the control sample had a higher mean mathematics TAKS; however, the students differed on a number of important covariates, as shown in Tables 1, 2, and 3. To account for the higher initial mean TAKS scores the students were leveled as part of the propensity score match process. The participants and the control sample were different on a number of covariates, but notable differences are in the percentages of students receiving GT, ESL, and LEP services. 
Table 1. Gender, ESL, LEP, and Gifted Characteristics Before Matching

\begin{tabular}{|c|c|c|c|}
\hline \multicolumn{2}{|c|}{ Characteristic } & \multirow{2}{*}{$\begin{array}{c}\text { Treatment } \\
50.2 \%\end{array}$} & \multirow{2}{*}{$\begin{array}{l}\text { Control } \\
52.0 \%\end{array}$} \\
\hline Gender & Male & & \\
\hline GT & Yes & $15.9 \%$ & $14.4 \%$ \\
\hline ESL & Yes & $12.3 \%$ & $9.2 \%$ \\
\hline LEP & Yes & $11.2 \%$ & $9.5 \%$ \\
\hline
\end{tabular}

Note. Before matching, Treatment $n=716$ and Control $n=856 . \mathrm{GT}=$ Gifted, ESL $=$ English Language Learner, LEP = Limited English Proficiency

Table 2. Grade Level of Unmatched Groups

\begin{tabular}{rrr}
\hline Grade & Treatment & Control \\
\hline 6th & $14.4 \%$ & $15.9 \%$ \\
7 th & $41.0 \%$ & $38.8 \%$ \\
8th & $44.6 \%$ & $45.3 \%$ \\
\hline
\end{tabular}

Note. Before matching, Treatment $n=716$ and Control $n=856$.

Table 3. Ethnicities of Students in Unmatched Groups

\begin{tabular}{ccc}
\hline Ethnicity & Treatment & Control \\
\hline Asian & $0.3 \%$ & $0.2 \%$ \\
African American & $29.0 \%$ & $26.8 \%$ \\
Hispanic & $59.3 \%$ & $63.4 \%$ \\
White & $11.4 \%$ & $9.5 \%$ \\
\hline
\end{tabular}

Note. Before matching, Treatment $n=716$ and Control $n=856$.

The ethnicity label of Hispanic or Latino refers to one of Cuban, Mexican, Puerto Rican, South or Central American, or other Spanish culture or origin, regardless of race (NCES, n.d.). On the other hand, race is a label of one who self-identifies as: (a) American Indian or Alaska Native, (b) Asian, (c) African American or Black, (d) Native Hawaiian or Other Pacific Islander, and (e) White (NCES, n.d.). Since the terms African American and Black are both used by the National Center for Educational Statistics and the Department of Education, African American was chosen to represent this group of students exclusively. These covariates were used to determine the students' probability of being in the treatment group; thus, treatment was the dependent variable. The overall fit of the binary logistic model was assessed by the Hosmer and Lemeshow chi-square test for goodness of fit. The test was non-significant at the .05 level; thus, it was concluded that the model fit the data adequately. 
The propensity scores were saved to the original SPSS files, and an SPSS macro was applied to match the treatment students to a pool of control students (Dattalo, 2010, p. 145). The aforementioned macro matched the treatment students to control students based on propensity scores generated by the logistic regression. The macro returned 500 matches, but only those with differences less than .0001 were considered. Thus, 109 matches were selected to be included in the analysis. After matching on propensity scores, the groups were more similar; Tables 4 through 6 represent the post-matched student scores. The initial experimental group contained 716 participants and the initial control group 856 participants $(n=1,572)$. After the propensity score matching procedure, both the experimental and control groups contained 109 participants, which yielded a new $n=218$.

Table 4. Gender, ESL, LEP, and Gifted Characteristics After Matching

\begin{tabular}{|c|c|c|c|}
\hline \multicolumn{2}{|c|}{ Characteristic } & Treatment & Control \\
\hline Gender & Male & $54.1 \%$ & $54.1 \%$ \\
\hline GT & Yes & $34.4 \%$ & $34.4 \%$ \\
\hline ESL & Yes & $2.8 \%$ & $2.8 \%$ \\
\hline LEP & Yes & $2.8 \%$ & $2.8 \%$ \\
\hline
\end{tabular}

Note. After matching, Treatment $n=109$ and Control $n=109 . \mathrm{GT}=$ Gifted, ESL $=$ English Language Learner, LEP = Limited English Proficiency

Table 5. Grade Level of Matched Groups

\begin{tabular}{ccc}
\hline Grade & Treatment & Control \\
\hline 6th & $0 \%$ & $0 \%$ \\
7th & $20.2 \%$ & $20.2 \%$ \\
8th & $79.8 \%$ & $79.8 \%$ \\
\hline
\end{tabular}

Note. After matching, Treatment $n=109$ and Control $n=109$.

Table 6. Ethnicities of Students in Unmatched Groups

\begin{tabular}{ccc}
\hline Ethnicity & Treatment & Control \\
\hline Asian & $0 \%$ & $0 \%$ \\
African American & $31.2 \%$ & $31.8 \%$ \\
Hispanic & $53.2 \%$ & $53.2 \%$ \\
White & $15.6 \%$ & $15.4 \%$ \\
\hline
\end{tabular}

Note. After matching, Treatment $n=109$ and Control $n=109$. 
Prior to conducting the ANOVA, the normality and equality of variances assumptions were assessed. The students' scores for this study were slightly positively skewed, with a coefficient of skewness of .258. A Shapiro-Wilk test was applied to test for normality of the data. The results were statistically significant; thus, it was concluded that the student data were not normal. However, after examining the histogram for the student data and the $Q-Q$ plot, the deviations from normal were not considered extreme. This is further substantiated by other researchers that contend that skewness and kurtosis values between -1 and +1 are within a tolerable range (Huck, 2012).

The results of the multi-way ANOVA were non-statistically significant for the treatment main effect: $F(1,206)=0.019, M S E=17.757, p=0.892$. The ethnicity main effect was statistically significant: $F(2,206)=12.399, M S E=17.757, p<.000$. The partial $\eta^{2}$ for the ethnicity main effect was 0.107 . Thus, approximately $10.7 \%$ of the variance in student performance could be attributed to ethnicity. The gender main effect was statistically significant: $F(1,206)=4.435$, $M S E=17.757, p<0.05$. The interaction effects were all non-statistically significant. The results of the Levene test were statistically significant; thus, the Games-Howell post hoc test was applied to identify differences among the different ethnicities. The results of the Games-Howell post hoc test indicated that there were statistically significant differences between all three ethnic groups in the study.

Table 7 presents the achievement increases across ethnicities. The data in Table 7 suggest that the integration of the IWB had a positive medium effect on the achievement of White students and a negative medium effect on African American students. Other notable differences included strong increases in mathematics TAKS scores, though not statistically significant.

One of the major concerns of No Child Left Behind (NCLB), and the school district wherein this study took place, was the difference in achievement across the different ethnic groups. Whether differences existed after the study was important, because closing the achievement gap is a significant issue in this school district, and the nation in general. Gaps in achievement were reduced for all groups except for African American students (see Table 8).

Table 7. Achievements Increases Across Ethnicities

\begin{tabular}{ccccccc}
\hline Ethnicity & $N$ & $\begin{array}{c}\text { Mean } \\
\text { Posttest }\end{array}$ & $\begin{array}{c}S D \\
\text { Posttest }\end{array}$ & $\begin{array}{c}\text { Mean } \\
\text { Pretest }\end{array}$ & $\begin{array}{c}S D \\
\text { Pretest }\end{array}$ & Cohen's d \\
\hline $\begin{array}{c}\text { African } \\
\text { American }\end{array}$ & 68 & 34.76 & 3.56 & 36.82 & 4.61 & -0.50 \\
Hispanic & 116 & 38.53 & 4.39 & 38.21 & 4.19 & 0.08 \\
White & 34 & 40.73 & 4.72 & 38.50 & 3.99 & 0.51 \\
\hline
\end{tabular}


Table 8. Gaps in Achievement After Treatment

\begin{tabular}{llll}
\hline Group & Mean 1 & Mean 2 & \multicolumn{1}{c}{$\Delta$} \\
\hline White/African American & 40.73 & 34.76 & 5.97 \\
White/Hispanic & 40.73 & 38.53 & 2.36 \\
Hispanic/African American & 38.53 & 34.76 & 3.77 \\
\hline
\end{tabular}

\section{Conclusion}

The implementation of the IWB in the classroom-learning environment has increased during the past decade (Manny-Ikan, Tikochinski, Zorman \& Dagan, 2011; Thomas, 2013). The IWB entered the classroom in the early '90s and has replaced the traditional chalk-/whiteboard in many classrooms. The IWB is a technology tool designed specifically for educational use and has become a focal point of many classroom interactions. The results of this study suggest that the IWB did not have a statistically significant direct effect on the achievement of all the students in this study. This may suggest that many teachers may lack the skills and training to utilize the many affordances of the tool to completely transform student achievement. Manny-Ikan et al., (2011) found that the introduction of IWB technology without sufficient training on the technology, as well as how to teach mathematics with the technology, could inhibit the benefits of the IWB in the classroom. The results of this study support the notion that technology in the mathematics classroom is a tool that is only beneficial when it is implemented purposefully.

The results of this study also support the notion that training on the IWB is necessary because the IWB should not be utilized in the same manner as the traditional chalk-/whiteboard; rather, the power of the IWB is in its ability to exploit the affordances for interactivity. Because many experienced IWB users may not develop the ability to fully exploit the affordances of the IWB due to the restraints of curriculum, time, and amount of preplanning necessary to use it (Hennessy, Deaney, Ruthven, \& Winterbottom, 2007), all teachers need content-specific training to maximize IWB functionality. In order for teachers to take full advantage of the pedagogical affordances of the IWB, teachers must develop a dynamic understanding of the features of the IWB and learn to interact fluidly with it during instruction (Al-Zaidiyeen, Lai, \& Fong-Soon, 2010; Martinez, 2010). It is important to note that such teacher training on IWB use will not produce instantaneous results. According to Desimone (2009), the effects of teacher professional development on student achievement occur in an indirect manner. Further, Desimone, Porter, Garet, Yoon, and Birman (2002) suggested that a four-year window is the minimum amount of time needed to begin to notice any differences in student achievement that stem from teacher professional development. The premise for these conclusions are the nature of teacher professional development and the time needed for teachers to practice, perfect, and begin to implement the new skills in the classroom.

Additionally, the results of this study indicate that the effects of the IWB were differentiated across ethnicities. Access to mobile devices such as cellular phones, smartphones, and tablet computers have rapidly changed the way the majority of learners consume and disseminate information (Liu et al., 2014). Unfortunately, access to technology is not universal. The reality is 
clear that students in urban schools who experience economic, linguistic, and/or other hardships, more often than their suburban, middle-class peers, lag in technology use and knowledge. Thus, one possible explanation for the large discrepancy in the achievement scores could be due to the fact that the IWB technology effects were mediated by student access to or comfort with technology.

Finally, mathematics teachers in urban settings face a challenging task of technology integration due to barriers such as: (a) the lack of knowledge and/or resources of how to align technology in their classrooms to the district's vague vision, (b) the lack of knowledge and/or resources of how to effectively make use of technology even when the teaching environment and infrastructure are not conducive, and (c) lack of training to integrate technology in the wake of lacking the requisite knowledge and skills to do so (Anthony \& Clark, 2011). Despite these obstacles, technology, when implemented effectively, is a catalyst for learning in the urban mathematics classroom. When urban students receive appropriate computer-assisted mathematics instruction, they substantively outperform their peers (Laffey, Espinosa, Moore, \& Lodree, 2003). In conclusion, the integration of IWB technology in mathematics classrooms must be accompanied by subject-specific training that leverages the affordances of the technology to meet the precise instructional needs of the teacher and the student. As the results of this study indicate, many variables must be accounted for in order to integrate IWB technology into an urban mathematics classroom. However, when these variables are accounted for, the mathematics instructional benefits of the IWB can be realized.

\section{Limitations and Suggestions for Further Research}

Several limitations require consideration regarding this study. One limitation of this study was the choice of IWB technologies available in the schools. Both school utilized a mobile IWB technology, which is problematic because it facilitates teacher underutilization of the tool. Because the teacher could simply remove the tool from the board, there is a possibility that the technology could be excluded from some lessons. However, to address this challenge weekly observations were conducted to ensure that the tools were functional and utilized in the classroom. The second limitation was the three different grade level assessments given in the study. Because teachers taught three different grade levels three different standardized assessments were included as outcome measures. To address this limitation students were matched using propensity score matching to ensure that there was a balanced participation across grade levels. Finally, the quality of each teacher was a limitation in this study. Like most educational and social science research, it is impossible to control all human related variables. In this study, the years of experience and other teacher qualifications were a possible limitation worth considering. However, an initial comparison of campus teacher credentials did not yield statistically significant differences across campuses.

\section{References}

Al-Onizat, S. H. (2016). Measurement of multiple intelligences among sample of students with autism, and intellectual disability using teacher estimation and its relationship with the variables: The type and severity of disability, gender, age, type of center. International Journal of Education, 8(1), 107-129. 
Al-Zaidiyeen, N., Lai, M., \& Fong-Soon, F. (2010). Teachers' attitudes and levels of technology use in classrooms: The case of Jordan Schools. International Education Studies, 3, 211218.

Armstrong, V., Barnes, S., Sutherland, R., Curran, S., Mills, S., \& Thompson, I. (2005). Collaborative research methodology for investigating teaching and learning: The use of the interactive whiteboard technology. Educational Review, 57(4), 457-469.

Bates, A. W. \& Poole, G. (2003). Effective teaching with technology in higher education: Foundations for success. Indianapolis, IN: Jossey-Bass.

Beauchamp, G. \& Kennewell, S. (2010). Interactivity in the classroom and its impact on learning. Computers \& Education, 54(3), 759-766. doi:10.1016/j.compedu.2009.09.03

Beauchamp, G. \& Kennewell, S. (2013). Transition in pedagogical orchestration using the interactive whiteboard. Education and Information Technologies, 18(2), 179-191.

Becker, H. J. (2001). How are teachers using computers in instruction? Retrieved on 3 September 2017 from www.crito.uci.edu/tlc/FINDINGS/special3/

Beeland, W. D. (2002, April). Student engagement, visual learning and technology: Can interactive whiteboards help? Paper presented at the annual conference of the Association of Information Technology for Teaching Education. Trinity College, Dublin, Ireland.

Bell, M. A. (2002). Why use an interactive whiteboard? A baker's dozen reasons! Retrieved on 3 September 2017 from http://teachers.net/gazette/JAN02

Brandt, R. (1995). Future shock is here. Educational Leadership, 53(2), 5-13.

Bunce, D. M., Flens, E. A., \& Neiles, K. Y. (2010). How long can students pay attention in class? A study of student attention decline using clickers. Journal of Chemical Education, 87, 1438-1443. http://dx.doi.org/10.1021/ed100409p

Chen, H.R., Chiang, C.H \& Lin, W.S. (2013). Learning effects of interactive whiteboard pedagogy for students in Taiwan from the perspective of multiple intelligences. Journal of Educational Computing Research, 49(2), 173-187.

Cheung, A. C. \& Slavin, R. E. (2012). How features of educational technology applications affect student reading outcomes: a meta-analysis. Educational Research Review, 7(3), 198-215.

Cheung, A. C. \& Slavin, R. E. (2013). The effectiveness of educational technology applications for enhancing mathematics achievement in K-12 classrooms: a meta-analysis. Educational Research Review, 9, 88-113

Dattalo, P. (2010). Strategies to approximate random sampling and assessment. New York, NY: Oxford University Press.

Demonte, T. (2013).Interactive whiteboards in the elementary classroom. International Society for Technology in Education. Retrieved on 3 September 2017 from http://www.iste.org/ docs/excerpts/IBOARD-excerpt.pdf

Desimone, L. M. (2009). Impact studies of teachers' professional development: Toward better conceptualizations and measures. Educational Researcher, 38(3), 181-199.

Desimone, L. M., Porter, A. C., Garet, M., Yoon, K. S., \& Birman, B. (2002). Does professional development change teachers' instruction? Results from a three-year study. Educational Evaluation and Policy Analysis, 24(2), 81-112. 
Digregorio, P. \& Sobel-lojeski, K. (2010). The effects of interactive whiteboards (IWB) on student performance and learning: A literature review. Journal of Educational Technology Systems, 38, 255-312. http://dx.doi.org/10.2190/ET.38.3.b

Drijvers, P. (2013). Digital technology in mathematics education: Why it works (or doesn't). PNA, 8(1), 1-20.

Erdogan, M., Kursun, E., Susman, G., Saltan, F., Gok, A., \& Yildiz, I. (2010). A qualitative study on classroom management and classroom discipline problems, reasons, and solutions: A case of information technologies class. Educational Sciences: Theory \& Practice, 10, 881891.

Gardner, H. (2001). Creators: multiple intelligences. In K. H. Pfenninger and V. R. Shubik (Eds.), The origins of creativity (pp. 117-144). New York, NY: Oxford University Press.

Glover, D., Miller, D., Averis, D., \& Door, V. (2007). The evolution of an effective pedagogy for teachers using the interactive whiteboard in mathematics and modern languages: An empirical analysis from the secondary sector. Learning, Media and Technology, 32(1), 520.

Goodnow J. \& Collins W. (1990). Development according to parents: The nature, sources and consequences of parents' ideas. London: Erlbaum.

Grady, M., Watkins, S., \& Montalvo, G. (2012). The effect of constructivist mathematics on achievement in rural Schools. Rural Educator, 33(3), 37-46.

Greiffenhagen, C. (2000, July). Interactive whiteboards in mathematics education: Possibilities and dangers. Paper presented at the 9th International Congress on Mathematical Education, Tokyo, Japan.

Hallett, D., Nunes, T., \& Bryant, P. (2010). Individual differences in conceptual and procedural knowledge when learning fractions. Journal of Educational Psychology, 102(2), 395-406. doi: $10.1037 / a 0017486$

Han W. J. (2007). The correlation between elementary school students' multiple intelligences and English reading proficiency", master thesis abstract, Retrieved on 3 September 2017 from: http://ndltd.ncl.edu.tw/cgi-bin/gs32/gsweb.cgi/ccd=q5.YaO/record?r1=1\&h1=4.

Hawkes, M. \& Cambre, M. (2001). Educational technology: Identifying the effects. Principal Leadership, 1, 48-51.

Hennessy, S., Deaney, R., Ruthven, K., \& Winterbottom, M. (2007). Pedagogical strategies for using the interactive whiteboards to foster learner participation in school science. Learning, Media and Technology, 32, 283-301.

Higgins, S., Beauchamp, G., \& Miller, D. (2007). Reviewing the literature on interactive whiteboards. Learning, Media and technology, 32(3), 213-225.

Hodge, S. \& Anderson, B. (2007). Teaching and learning with an interactive whiteboard: A teacher's journey. Learning, Media and Technology, 32(3), 271-282.

Hsin, C.T., Li, M.C. \& Tsai, C.C. (2014). The influence of young children's use of technology on their learning: A review. Journal of Educational Technology \& Society, 17(4), 85-99.

Huck, S. W. (2012). Reading statistics and research. Boston, MA: Pearson Education. 
Jacobsen, M., Clifford, P., \& Friesen, S. (2002). Preparing teachers for technology integration: Creating a culture of inquiry in the context of use. Contemporary Issues in Technology and Teacher Education, 2(3) 363-388.

Jones, M. H., Irvin, M. J., \& Kibe, G. W. (2012). Does geographic setting alter the roles of academically supportive factors? African American adolescents' friendships, math selfconcept, and math performance. Journal of Negro Education, 81(4), 319-337

Keengwe, J. \& Akyeampong, A. (2010). Technology integration barriers in K-12 urban classrooms. In G. Siemens \& B. Dodge (Eds.), Proceedings of Society for Information Technology \& Teacher Education International Conference (pp. 2267-2271). Chesapeake, VA: AACE.

Kennewell, S., Tanner, H., Jones, S., \& Beauchamp, G. (2008). Analyzing the interactive technology to implement interactive teaching. Journal of Computer Assisted Learning, 24, 61-73.

Kidd, T. \& Jared, K. (2010). Technology integration and urban schools: Implications for instructional practices. International Journal of Information and Communication Technology Education, 6, 51. http://dx.doi.org/10.4018/jicte.2010070105

Laffey, J. M., Espinosa, L., Moore, J., \& Lodree, A. (2003). Supporting learning and behaviour of at-risk young children: Computers in urban education. Journal of Research on Technology in Education, 35(4), 423-440.

Lee, M. Y. (2006). A study of college students' multiple intelligences, self-efficacy and learning intention, master thesis abstract, Retrieved on 3 September 2017 from: http://ndltd. ncl.edu.tw/cgi-bin/gs32/gsweb.cgi/ccd=q5.YaO/record?r1=1\&h1=5.

Littleton K., Twiner A., \& Gillen J. (2010). Instruction as orchestration: Multimodal connection building with the interactive whiteboard, pedagogies: An International Journal, 5(2), 130-141.

Liu, M., Scordino, R., Geurtz, R., Navarrete, C., Ko, Y., \& Lim, M. (2014). A look at research on mobile learning in $\mathrm{K}-12$ education from 2007 to the present. Journal of Research on Technology in Education, 46(4), 325-372.

Manny-lkan, E., Tikochinski, T., Zorman, R., \& Dagan, O. (2011). Using the interactive whiteboard in teaching and learning - An evaluation of the SMART classroom pilot project. Interdisciplinary Journal of E-Learning \& Learning Objects, 7, 249-273.

Martinez, M. (2010). Teacher education can't ignore technology. Phi Delta Kappan, 92, 74-75.

Mercer, N., Warwick, P., Kershner, R., Kershner, S., \& Kleine, J. (2010). Can the interactive whiteboard help provide 'dialogic space' for children's collaborative activity? Language and Education, 24(5), 367-384.

Miller, D. \& Glover, D. (2002). The interactive whiteboard as a force for pedagogic change: The experience of five elementary schools in an English Education Authority. Information Technology in Childhood Education Annual, 2002(1), 5-19.

Morris, D. (2010). Are teachers technophobes? Investigating professional competency in the use of ICT to support teaching and learning. Procedia-Social and Behavioral Sciences, 2(2), 4010-4015. doi:10.1016/j.sbspro.2010.03.632 
National Center for Educational Statistics. (n.d.). Statistical standards: Defining race and ethnicity data. Retrieved on 3 September from http://nces.ed.gov/statprog/2002/ std1_5.asp

Razmjoo S. A. (2008). On the relationship between multiple intelligences and Language success, The Reading Matrix, 8(2), 155-174.

Rosenbaum, P.R. (1998). Propensity score. Retrieved on 3 September 2017 from http://libproxy.library.unt.edu:2056/doi/10.1002/9781118445112.stat05196.pub2/full

Rosenbaum, P. R. \& Rubin, D. B. (1983). The central of the propensity score in observational studies for causal effects. Biometrika, 70, 41-44.

Sarsa, J. \& Soler, R. (2011). Special features of interactive whiteboard software for motivating students. International Journal of Information and Education Technology, 1(3), 235-240.

Schneiter, K. (2010). Preparing teachers to use technology: Considerations from a capstone mathematics and technology course. Contemporary Issues in Technology and Teacher Education, 10(4), 457-469.

Shadish W. R., Cook, T. D., \& Campbell, D. T. (2002). Experimental and quasi-experimental designs for generalized causal inference. Boston, MA: Houghton Mifflin.

Thomas, J.A. (2013). A mixed methods case study of the levels of interactive whiteboard use by K-12 teachers (Doctoral Dissertation). Retrieved from ProQuest. (3580526)

Torff, B. \& Tirotta, R. (2010). Interactive whiteboards produce small gains in elementary students' self-reported motivation in mathematics. Computers \& Education, 54, 379383. doi: 10.1016/j.compedu.2009.08.019

Turel, Y. K. \& Johnson, T. E. (2012). Teachers' belief and use of interactive whiteboards for teaching and learning. Educational Technology \& Society, 15(1), 381-394.

Walker, D. (2002). Meet Whiteboard Wendy. Times Educational Supplement, 13, 13-22.

Wall, K., Higgins, S., \& Smith, H. (2005). The visual helps me understand the complicated things: Pupils' views of teaching and learning with interactive whiteboards, British Journal of Educational Technology, 36(5), 851-867.

Winzenried, A., Dalgarno, B., \& Tinkler, J. (2010). The interactive whiteboard: A transitional technology supporting diverse teaching practices. Australasian Journal of Educational Technology, 26(4), 534-552.

Whyte, S., Beauchamp, G., \& Alexander, J. (2014). Researching interactive whiteboard (IWB) use from primary school to university settings across Europe: an analytical framework for foreign language teaching. Cylchgrawn Addysg Prifysgol Cymru/University of Wales Journal of Education, 17(1), 30-52.

Wood, D. (1998). How children think and learn (2nd ed.). Oxford, United Kingdom: Blackwell.

Wood, R. \& Ashfield, J. (2008). The use of the interactive whiteboard for creative teaching and learning in literacy and mathematics: A case study. British Journal of Educational Technology, 39(1), 84-96.

Young, J.R. \& Young, J.L. (2012). "But that's not fair": Teacher technology readiness and African American Students'. The Journal of the Texas Alliance of Black School Educators, 4(1), 19-32. 
Correspondence: Jamaal Young, Associate Professor, Department of Teacher Education and Administration, College of Education, University of North Texas, Denton, Texas, USA. 